\title{
Reduction in Cooling Load by Using Passive Cooling Technique for Conference Hall
}

\author{
Gulab Chand Sahu', Abhishek Kumar Jain² \\ ${ }^{1}$ Assistant Professor, department of Mechanical Engineering, Kruti Institute of Technology and Engineering, Raipur (C.G.) 492001 \\ ${ }^{2}$ Head \& Assistant professor, Department of Mechanical Engineering, Kruti Institute of Technology and Engineering, Raipur (C.G.) 492001
}

\begin{abstract}
Passive cooling technique uses non-mechanical methods to maintain a comfortable indoor temperature. Passive cooling techniques can be reduced the peak cooling load in buildings, thus reducing the size of the air conditioning apparatus and the period for which it is usually required thereby affecting the impact on the environment. This paper presents cooling load calculation by using CLTD method for a conference hall. The cooling load calculation has been worked out by considering various parameters. The calculation has been worked out using MS-Excel program. The results so obtained have been compared with those of simulation technique HAP 4.5. It is a computer based program developed by Carrier Company which aids in calculating the cooling load based on ASHRAE standards. After obtaining cooling load, a system is installed in the conditioned space to reduce the cooling load which results in energy saving, cost saving and also the reduction in $\mathrm{CO} 2$ emission. This system is ground water heat exchanger which circulates the ground water though the pipe in the wall and reduces the inside temperature which ultimately reduces the cooling load. MAT LAB software is using for estimating various parameters of Ground Source Heat Pump.
\end{abstract}

Keywords: Cooling Load Temperature Difference, Cooling Load, Air Conditioning, and Ground Source Heat Exchanger

\section{Introduction}

In the past two decades, technology of energy foundations and other thermo-active ground-source systems has developed immensely yet Austria is still pioneering. Since 2005 more than 7,000 energy piles per year have been installed, presently resulting in a total number of approx 100,000 energy piles, ranging from small diameter driven piles to large diameter bored piles. In fact "Energy diaphragm walls" (slurry ditch walls) have become a frequently used alternative to energy piles in Austria [1]. Along with the development of the modern society a very serious problem is energy shortage. Renewable and sustainable energy offers a feasible and effective solution to counter the effects of this problem. Due to their higher energy consumption efficiencies, it has been used for years in developed and developing countries replacing or as a supplementary to the conventional air conditioning systems. GSHP systems are clean technologies using renewable energy resources. Due of the imbalance of cooling and heating demands in the residential and commercial buildings in a year, the Ground Source Heat Pump systems must be integrated with other additional energy storage systems in cooling-dominated or heating-dominated areas. For the efficient utilization of renewable energy and energy conservation the use of TES systems are strategic and use of other necessary technologies is necessary [1]. In the past decade awareness of climate change and environmental pollution issues has increased dramatically. Interest in utilizing alternative energies to improve energy competence and reduce ecological risks is growing rapidly. Geothermal energy utilized by ground source heat pumps (GSHP also well-known as geothermal heat pump, includes systems that deliver either heat or cooling to the end user) is a new and promising energy available. It is environmentally friendly, low life-safety risk and has low maintenance cost. Heat pumps employ work to transport energy from a cold source to a warm sink. A GSHP typically uses the ground as a heat source during the heating season and a heat sink during the cooling season [2]. Commercial and institutional buildings represent $12 \%$ of all secondary energy use, with $50 \%$ of this total going to towards space heating and space cooling. Offices account for over $40 \%$ of the floor area in this sector, and therefore represent a prominent target for energy use reductions [3]. In the building the conventional ground heat exchanger is extracted from the soil by means of heat pump. The ground operates as heat source supplying warm energy to building during winter season, while in summer it treated as heat sink when cold energy of building is required. There are two types of conventional ground heat exchangers. The $1^{\text {st }}$ is open loop system where the groundwater is used as a heat carrier and pumped directly from an aquifer to the heat pump. The $2^{\text {nd }}$ is closed loop arrangement where closed-coils absorber pipes are surrounded into borehole, laid either horizontally or vertically [4].

\subsection{Passive Cooling Technology}

Set Building, energy and environment are the key issues in the developing country like India, and recently, there has been rising interest in analyzing the solar heat gains and energy use inside the building envelop. Without affecting the indoor environmental quality (IEQ), the research aids to reduce energy use by adopting different building elements with enhanced thermal performance and thus reducing the size of the air conditioning system. The energy crisis in developing countries for the duration of summer season is mainly due to cooling load requirement in buildings. To reduce the cooling load, passive cooling structural design is the most sustainable method [9].

The merits of Passive Cooling Techniques are mentioned as under they enhance utilization of Non-Conventional Energy Sources like Sun, Wind etc. They are green technology(s), 


\section{International Journal of Science and Research (IJSR) \\ ISSN (Online): 2319-7064 \\ Index Copernicus Value (2015): 78.96 | Impact Factor (2015): 6.391}

hence, are technically cleaner, i.e. Non-Polluting. They often incorporate very less or no running costs.

\subsection{Ground Source Heat Pump and Heat Exchanger}

Central heating and/or cooling system that transfers heat to or from the ground by means of geothermal heat pump or ground source heat pump (GSHP). Earth is uses as a heat source in the winter session or a heat sink in the summer session. Open systems directly utilize the ground's thermal storage medium. Ground water is pumped from a well to the Heating system to provide thermal energy to the secondary component with the help of the heat pump. Once the heating operation, water (at a significantly unusual temperature) is either injected back into the aquifer (using a second well) or predisposed off in surface water bodies. Although these systems have been widely used and involve lower initial costs, technical long-term high financial, technical environmental risks have become apparent.

\section{Practical Evaluation}

This project use the direct circulation of ground water from $80 \mathrm{~m}$ depth rather the use of energy pile system, which work on the temperature difference between soil and water. There is direct circulation of ground water through circulating pump due the temperature gradient between the ground water and cooling space temperature the heat transfer takes from Cooling space to the ground water and due to this heat transfer activity the cooling space maintained at comfortable temperature. The proposed system and circulation of pipe on the wall is given in figure (1).

The circulating pump suck the water from the sump level which is $80 \mathrm{~m}$ below to the ground level and circulating the water through the pipe, the pipe is placed between the two wall of the conditioned space and extracting heat from the room.

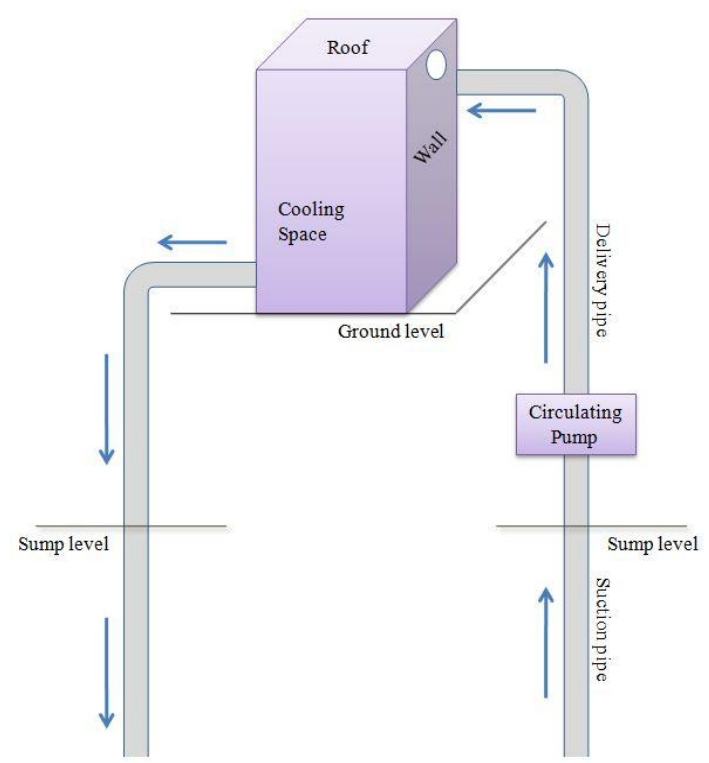

Figure 1: GSHP System

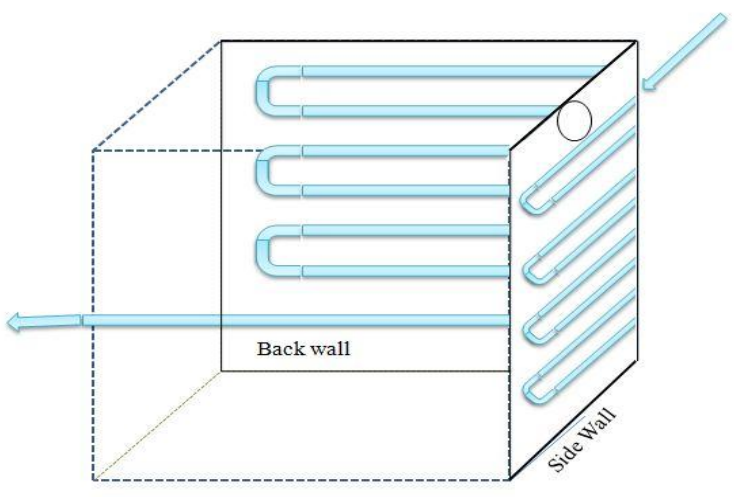

Figure 2: Circulation of pipe on the wall

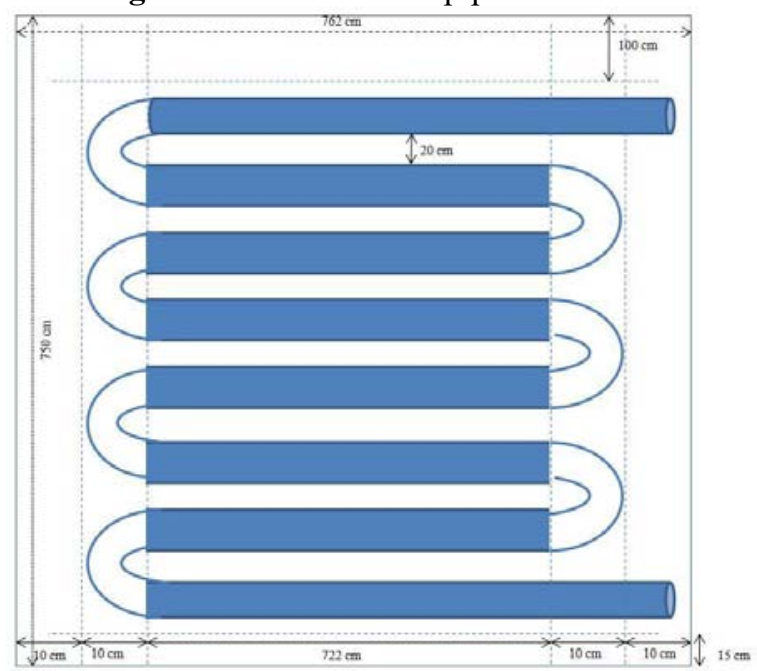

Figure 3: Position of GHE in wall

A various number of parameters have an influence on the ground heat exchanger performance, especially the GHE length and the rate of flow.

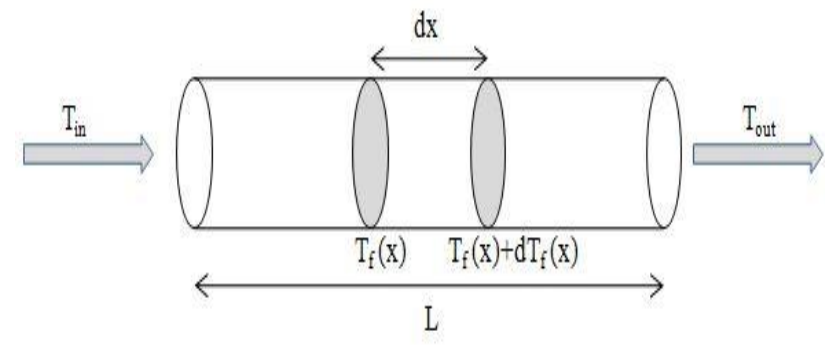

Figure 4: Diagram of Heat Exchanger Pipe

In the analytical model we will thus consider only the heat exchange which is done in fixed system. The heat exchange rate within the pipe is making by forced convection. We consider an infinitesimal element $\mathrm{dx}$ of a pipe in the coolant flow in figure (4).

The experimental heat exchange rate is calculated by the following equation

$$
Q=\mathrm{m} \times c_{p} \times\left(T_{\text {out }}-T_{\text {in }}\right)
$$

The system estimating cooling load of any building there are some basic information are necessary to design an exact HVAC systems, like building orientation, weather condition, building spacing, buildings resources etc. The more accurate the information will be the load estimated. Considered a 


\section{International Journal of Science and Research (IJSR) \\ ISSN (Online): 2319-7064 \\ Index Copernicus Value (2015): 78.96 Impact Factor (2015): 6.391}

conference hall for analysis, which is positioned in the multistory building (Case: Nagar Nigam Raipur) situated in Raipur and located at $81.63^{\circ} \mathrm{E}$ longitude and $21.23^{\circ} \mathrm{N}$ latitude in Raipur District of Chhattisgarh, India at an elevation of about 296 meters above mean sea level.

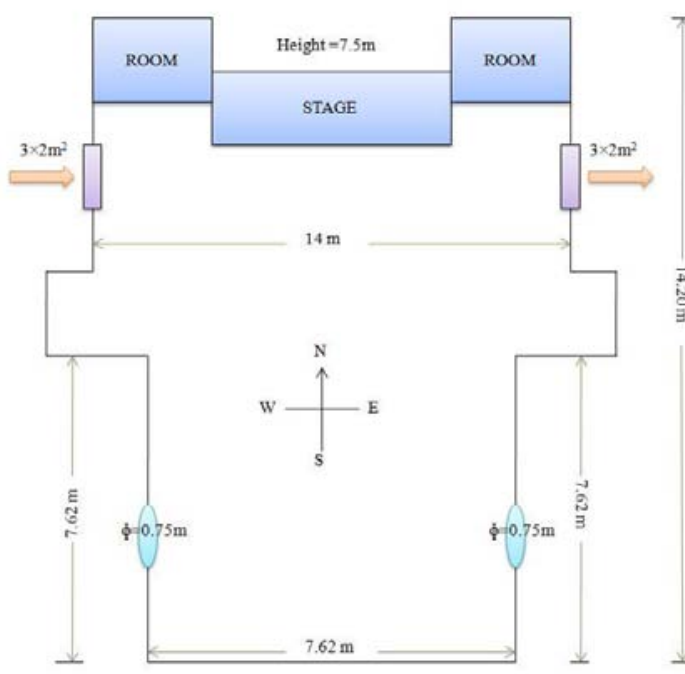

Figure 5: Layout of Nagar Nigam

Conference Hall

Raipur has a " tropical Hot and dried out weather" temperature remain reasonable all through the year,except from March to June, which can be extremely hot .The temperature in April-June sometimes raise above the $46{ }^{\circ} \mathrm{C}$ .These summer month also have hot and dry wind, in the summer the temperature may also cross the $48{ }^{\circ} \mathrm{C}$. The average rain fall in the Raipur city is $1300 \mathrm{~mm}$ mostly in the Monson season from late June to early October. Winter last from November to January.

\section{Problem Identification}

The objective of this work is to calculate cooling load for a known condition space $\&$ another problems are identified are follows:

1) To form the basis for building energy analysis.

2)Optimization of Mass flow rate for water for building cooling.

3) Outcome on cooling rate due to circulation of pipe arrangement.

4)Effect on cooling rate on the variation of elevation of the structure.

5)To apply the GSHP system on a building in Tropical condition for cooling purpose.

6)Determination of reducing in cooling load due to proposed Ground water heat pump system.

7) Analysis of reduction of $\mathrm{CO} 2$ emission to the atmosphere by using proposed Ground source heat pump.

8) To determine the payback period of the system.

\section{Equation}

To design of any apparatus there is need of various parameters. And for this system essential parameters are mass flow rate, velocity of fluid, discharge, length of pipe, diameter of pipe, Reynolds no., friction factor, etc. The governing equations for the ground water heat exchanger are given below:

Selection of suitable mass flow rate

$$
\mathrm{m}=\rho_{w} \times A_{p} \times V
$$

Where,

$\dot{\mathrm{m}}=$ mass flow rate $(\mathrm{kg} / \mathrm{s})$

$\rho_{\mathrm{w}}=$ density of water $\left(\mathrm{kg} / \mathrm{m}^{3}\right)$

$A_{p}=$ cross section area of pipe $\left(\mathrm{m}^{2}\right)$

$\mathrm{V}=$ velocity of water in pipe $(\mathrm{m} / \mathrm{s})$

Determination of Reynolds Number

$R_{e}=\frac{V d}{v}$

Where,

$\mathrm{d}_{\mathrm{i}}=$ Inner diameter of pipe $(\mathrm{m})$

$\mathrm{d}_{\mathrm{o}}=$ outer diameter of pipe $(\mathrm{m})$

${ }^{\circ}=$ kinematic viscosity of water at $25{ }^{\circ} \mathrm{C}$

Calculation of inside heat transfer coefficient

$N_{u}=\frac{h_{i} d_{i}}{k_{w}}$

$\mathrm{h}_{\mathrm{i}}=$ Convective heat transfer coefficient at inside the pipe $\left(\mathrm{W} / \mathrm{m}^{2} \mathrm{~K}\right)$

$\mathrm{k}_{\mathrm{w}}=$ thermal conductivity of water at $25^{\circ} \mathrm{C}$

Calculation of overall heat transfer coefficient

$$
U=\frac{1}{\frac{1}{h_{o}}+\frac{x_{p}}{k_{p}}+\frac{r_{o}}{k_{\text {pipe }}}+\ln \frac{r_{o}}{r_{i}}+\frac{r_{o}}{h_{i} r_{i}}}
$$

Where,

$\mathrm{U}=$ overall heat transfer coefficient $\left(\mathrm{W} / \mathrm{m}^{2} \mathrm{~K}\right)$

$\mathrm{x}_{\mathrm{p}}=$ thickness of plaster $(\mathrm{m})$

$\mathrm{k}_{\mathrm{p}}=$ thermal conductivity of pipe $(\mathrm{W} / \mathrm{mK})$

$\mathrm{h}_{\mathrm{o}}=$ Convective heat transfer coefficient at outside the pipe $\left(\mathrm{W} / \mathrm{m}^{2} \mathrm{~K}\right)$

Calculation of Heat transfer rate

$$
\mathrm{Q}=\dot{\mathrm{m}} \times \mathrm{c}_{\mathrm{pw}} \times\left(\mathrm{T}_{\text {out }}-\mathrm{T}_{\text {in }}\right)
$$

Where,

$\mathrm{Q}=$ heat transfer rate $(\mathrm{Watt})$

$\mathrm{c}_{\mathrm{pw}}=$ specific heat of water at constant pressure $(\mathrm{kJ} / \mathrm{kgK})$

$\mathrm{T}_{\text {out }}=$ outlet fluid temperature from heat exchanger $\left({ }^{\circ} \mathrm{C}\right)$

$\mathrm{T}_{\text {in }}=$ inlet fluid temperature to heat exchanger $\left({ }^{\circ} \mathrm{C}\right)$

Requirement of Pump Power

Power of centrifugal pump is given by the following equation:

Power $=\dot{\mathrm{mgH}}$

Where,

$\mathrm{g}=$ acceleration due to gravity $\left(\mathrm{m} / \mathrm{sec}^{2}\right)$

$\mathrm{H}=$ head against pump is working $(\mathrm{m})$

Head calculation of Centrifugal pump

$$
\mathrm{H}=\mathrm{h}_{\mathrm{s}}+\mathrm{h}_{\mathrm{d}}+\mathrm{h}_{\mathrm{fs}}+\mathrm{h}_{\mathrm{fd}}
$$

Where

$\mathrm{h}_{\mathrm{s}}=$ loss of head in suction pipe $(\mathrm{m})$

$\mathrm{h}_{\mathrm{d}}=$ loss of head in delivery pipe $(\mathrm{m})$

loss of head due to friction in suction pipe $(\mathrm{m})$ 


$$
h_{f s}=\frac{4 f l_{s} V^{2}}{2 g d_{i}}
$$

loss of head due to friction in delivery pipe $(\mathrm{m})=$

$$
h_{f d}=\frac{4 f l_{d} V^{2}}{2 g d_{i}}
$$

$\mathrm{f}=$ coefficient of friction

\section{Calculation}

The general step by step procedures for Heat Transfer Analysis are as follows: Select inside design condition (Temperature, relative humidity). Select outside design condition (Temperature, relative humidity). Determine the overall heat transfer coefficient $U$ for wall, and roof. Calculate area of wall, ceiling, floor, door, windows. Calculate heat gain from transmission. Calculate solar heat gain. Calculate sensible and latent heat gain from ventilation, infiltration and occupants. Calculate lighting heat gain. Calculation of Total Heat Gain. Calculation of TR.

Hand calculations were done for a small portion of the building. In the Nagar Nigam Conference Hall is treated as separate system. All equations required for heat transfer through the building and for the indoor condition were used to get the thermal load. Then, all the equations were insert in a particular program MS Excel, to get the results.

$$
\mathrm{Q}_{\text {Total }}=\mathrm{Q}_{\text {Fabric }}+\mathrm{Q}_{\text {Infiltration }}+\mathrm{Q}_{\text {Ventilation }}+\mathrm{Q}_{\text {Electrical }}+\mathrm{Q}_{\text {Occupant }}
$$

Load calculation for the various sources mention in the

\begin{tabular}{|c|c|c|c|c|c|c|}
\hline \multirow{2}{*}{ S.N. } & \multirow{2}{*}{ Months } & \multicolumn{4}{|c|}{ Wall Facing } & \multirow{2}{*}{ Roof } \\
\hline & & $\mathrm{N}$ & E & $\mathrm{S}$ & W & \\
\hline 1 & March & 0.48 & 0.45 & 0.37 & 0.37 & 19.73 \\
\hline 2 & April & 0.51 & 0.47 & 0.39 & 0.38 & 20.08 \\
\hline 3 & May & 0.57 & 0.50 & 0.42 & 0.42 & 20.78 \\
\hline 4 & June & 0.63 & 0.53 & 0.45 & 0.45 & 21.48 \\
\hline
\end{tabular}
equation [] are given below in tables with month wise.

Table 1: Heat gain through the Walls \& Roof in $\mathrm{kW}$

Table 2: Heat gain due to infiltration \& Ventilation in $\mathrm{kW}$

\begin{tabular}{|c|c|c|c|c|c|}
\hline \multirow{2}{*}{ S.N. } & \multirow{2}{*}{ Months } & \multicolumn{2}{|c|}{ Infiltration } & \multicolumn{2}{c|}{ Ventilation } \\
\cline { 3 - 6 } & & Q1 & Qs & Q1 & Qs \\
\hline 1 & March & 12.73 & 10.67 & 7.17 & 6.01 \\
\hline 2 & April & 11.91 & 11.43 & 6.71 & 6.44 \\
\hline 3 & May & 15.62 & 12.95 & 8.80 & 7.30 \\
\hline 4 & June & 24.23 & 14.48 & 13.65 & 8.16 \\
\hline
\end{tabular}

Table 3: Heat gain through electrical \& occupants in $\mathrm{kW}$

\begin{tabular}{|c|c|c|c|c|}
\hline \multirow{2}{*}{ S.N. } & \multirow{2}{*}{ Months } & Electrical & \multicolumn{2}{|c|}{ Occupants } \\
\cline { 3 - 5 } & & $\mathrm{Q}$ & $\mathrm{Q} 1$ & Qs \\
\hline 1 & March & 3.69 & 3.02 & 3.99 \\
\hline 2 & April & 3.69 & 3.02 & 3.99 \\
\hline 3 & May & 3.69 & 3.02 & 3.99 \\
\hline 4 & June & 3.69 & 3.02 & 3.99 \\
\hline
\end{tabular}

From the above table total cooling load for conference hall is given below in table (4)

Table 4: Total cooling load in $\mathrm{kW}$

\begin{tabular}{|c|c|c|c|c|c|c|c|}
\hline S.N. & Months & Fabric & Infiltration & Ventilation & Electrical & occupants & Total \\
\hline 1 & March & 21.40 & 23.40 & 13.18 & 3.69 & 7.01 & 68.68 \\
\hline 2 & April & 21.83 & 23.34 & 13.15 & 3.69 & 7.01 & 69.02 \\
\hline 3 & May & 22.69 & 28.57 & 16.10 & 3.69 & 7.01 & 78.06 \\
\hline 4 & June & 23.54 & 38.71 & 21.81 & 3.69 & 7.01 & 94.76 \\
\hline
\end{tabular}

From the table (4) total cooling load is calculated 27 TR.

\section{Results and Conclusion}

The deviation of heat gain between results obtained from two different i.e. CLTD method and HAP program methods are shown in Figure [6] It shows that there are little different between two methods and result are satisfactory as ASHRAE standards. To establish the cooling power, a various parameters need to be recognized in order to achieve the analysis. These important parameters are the Cooling load (Q), Working hour of system, COP of the system, Inlet Temperature of ground water, Outlet temperature of water through the heat exchange, Heat transfer between the conditioned space, atmospheric climatic condition. In this study only theoretical analysis will be provided. In order to determine the reduction in consumption of cooling power by installation of Ground water heat exchanger, the number of air conditioner can be reduced and due to reduction of air conditioner directly the reduction of $\mathrm{CO}_{2}$ emission can be calculated. As there should be prior information of some parameter (like Ground water temperature, ambient temperature, COP of air conditioner ) and some derived parameter ( i.e. Heat transfer through the space to the ground water, Cooling load ) are to be find out in the previous chapter.

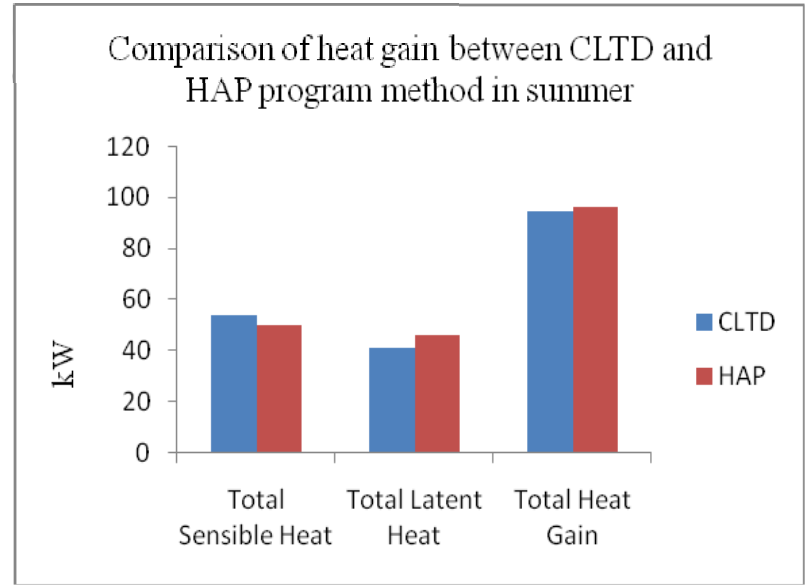

Figure 6: Variation of heat gain between CLTD and HAP program

The climate of Raipur is tropical. It is hot and humid because of its proximity to the Tropic of Cancer, temperatures remain 


\section{International Journal of Science and Research (IJSR) \\ ISSN (Online): 2319-7064}

Index Copernicus Value (2015): 78.96 | Impact Factor (2015): 6.391

moderate throughout the year, except from March to June, which can be exceptionally hot. The temperature in AprilMay at times rises above $48^{\circ} \mathrm{C}$. In summers, the temperature can also go up to $48{ }^{\circ} \mathrm{C}$. Hence needs of space cooling in the summer months and proposed system is suggested for Raipur city. The results conclude that the total cooling load for the Nagar Nigam, conference hall is 27 tons for summer (May to June), which is approximately same, comparing with the AC required tonnage calculated by HAP 4.50 software.

The Ground Water Heat Exchanger is an open type system. It is circulated ground water to building wall through the pipe and remove heat about $14 \mathrm{~kW}$ from the conditioned space. Various parameters are analyzed in MAT Lab; the feasible values are shown in table 6.1 that obtained by maintaining rate of flow at $0.7 \mathrm{~kg} / \mathrm{s}$ for the room temperature according to human comfort.

Table 5: Various parameters and their values

\begin{tabular}{|c|c|c|}
\hline S.N. & Parameters & Values obtained \\
\hline 1 & Mass flow rate $(\dot{\mathrm{m}})$ & $0.7 \mathrm{~kg} / \mathrm{s}$ \\
\hline 2 & Velocity of flow $(\mathrm{V})$ & $1.38 \mathrm{~m} / \mathrm{s}$ \\
\hline 3. & Time of each circulation $(\mathrm{t})$ & $5.1 \mathrm{~min} /$ circulation \\
\hline 4 & Outlet temperature of fluid in pipe $\left(\mathrm{T}_{\text {out }}\right)$ & $29.8^{\circ} \mathrm{C}$ \\
\hline 5 & Total head of pump $(\mathrm{H})$ & $113 \mathrm{~m}$ \\
\hline 6 & Power required $(\mathrm{P})$ & $\begin{array}{c}1.5 \mathrm{HP} \text { for better } \\
\text { functioning }\end{array}$ \\
\hline
\end{tabular}

Energy saving per annum for Raipur city has been found $3605 \mathrm{kWh}$ at consideration size of space $1491 \mathrm{~m}^{3}$.

By electricity saving of $3506 \mathrm{kWh}$, the saving of coal is $3506 \mathrm{~kg}$ that leads to reduction in $\mathrm{CO}_{2}$ emission of $9950 \mathrm{~kg}$ per year for the same space.

With the annual saving of Rs 21630, the reimbursement time of the Ground Source Heat Pump system has been calculated as 5.03 years for the 4 month working in a year.

\section{References}

[1] Heinz Brandl, Thermo-Active Ground-Source Structures for Heating and cooling, (Structures and Techniques), (2013).

[2] HuaQian, YungangWang, Modeling the interactions between the performance of ground source heat pumps and soil temperature variations, (Energy for Sustainable Development), (8 August 2014).

[3] Justin Tamasauska,, Martin Kegel, Roberto Sunye, An analysis of solar thermal technologies integrated into a Canadian office building, (International Conference on Solar Heating and Cooling for Buildings and Industry), (23-25 September 2013).

[4] M.E. Suryatriyastuti, H. Mroueh, S. Burlon, Understanding the temperature-induced mechanical behavior of energy pile foundations (Renewable and Sustainable Energy Reviews), (20 February 2012).

[5] $\mathrm{Na} \mathrm{Zhu,} \mathrm{Pingfang} \mathrm{Hu}$, LinghongXu, Zhangning Jiang, Fei Lei, Recent research and applications of ground source heat pump integrated with thermal energy storage systems: a review, (Applied Thermal Engineering), (21
June 2014).

[6] C.K. Lee, H.N. Lam, A simplified model of energy pile for ground-source heat pump Systems, (Energy), (10 March 2013).

[7] Monique de Moel , Peter M. Bach , Technological advances and applications of geothermal energy pile foundations and their feasibility in Australia, (Renewable and Sustainable Energy Reviews),( 15 July 2010).

[8] Christopher J. Wood, Hao Liu, Saffa B. Riffat, An investigation of the heat pump performance and ground temperature of a piled foundation heat exchanger system for a residential building, (Energy), (19 August 2010).

[9] Kulkarni K., P.K. Sahoo and Mishra M., "Optimization of cooling load for a lecture theatre in a composite climate in India" Energy and Buildings, 2011; 43; 15731579.

[10] Andersson,B., Wayne P. and Ronald K., " The impact of building orientation on residential heating and cooling", Energy and Buildings, 1985; 8; 205-224.

[11]Al-Rabghi,O. and Khalid A. , " Utilizing transfer function method for hourly cooling load calculations" Energy Conversion and Management,1997; 38; 319-332.

[12] Suziyana M. D., Nina S. N., Yusof T. M. and. Basirul A. A. S., "Analysis of Heat Gain in Computer Laboratory and Excellent Centre by using CLTD/CLF/SCL Method" Procedia Engineering, 2013; 53; 655 - 664 .

[13]Hani H. Sait, "Estimated Thermal Load and Selecting of Suitable Air-Conditioning Systems for a Three Story Educational Building" Procedia Computer Science, $2013 ; 19 ; 636-645$

[14]Foudaa A., Melikyan Z., Mohamed M.A. and Elattar H.F., "A modified method of calculating the heating load for residential buildings" Energy and Buildings, 2014; $75 ; 170-175$.

[15]Duanmu L., Wang Z., ZhaiZ.andXiangli L., "A simplified method to predict hourly building cooling load for urban energy planning" Energy and Buildings, 2013; 58; 281-291.

[16]Christian A., Gueymard and Thevenard D., "Monthly average clear-sky broadband irradiance database for worldwide solar heat gain and building cooling load calculations" Solar Energy, 2009; 83; 1998-2018.

[17] Westphal,F.S. and Roberto L., "The use of simplified weather data to estimate thermal loads of non-residential buildings" Energy and Buildings, 2004; 36; 847-854.

[18] Mui K.W. and Wong L.T. "Cooling load calculations in subtropical climate" Building and Environment, 2007; 42; 2498-2504.

[19] Francesco C., Stefano P.C., Marco F. and Bjarne W.O., "Solar radiation and cooling load calculation for radiant systems: Definition and evaluation of the Direct Solar Load" Energy and Buildings 2010; 42; 305-314.

[20] ASHRAE 1997 "Cooling Load Calculations" Chapter $28 ; 28.1-28.65$. 